\title{
Ultrasound-guided Percutaneous Irreversible Electroporation for Treatment of Locally Recurrent Pancreatic Cancer After Surgical Resection
}

\author{
CHRISTOPHER MÅNSSON ${ }^{1}$, ANDERS NILSSON $^{1}$, PETER NYGREN $^{2}$ and BRITT-MARIE KARLSON ${ }^{1}$ \\ ${ }^{1}$ Department of Surgical Sciences, Uppsala University, Uppsala, Sweden; \\ ${ }^{2}$ Department of Immunology, Genetics and Pathology, Uppsala University, Uppsala, Sweden
}

\begin{abstract}
Background/Aim: Irreversible electroporation (IRE) has recently been used as an experimental treatment for cancers including locally advanced pancreatic cancer. There is very limited data on IRE in pancreatic cancer that is locally recurrent after surgical resection. The aim of this study was to evaluate the safety and efficacy of IRE in this setting. Patients and Methods: Ten patients with locally recurrent pancreatic cancer without distant metastases after surgical resection were included and treated with ultrasound-guided percutaneous IRE. Results: Two patients had severe complications, of whom one died. Median disease-free survival was 3.3 months and overall median survival after IRE and resection was 16.5 and 42.7 months, respectively. Two patients are alive 42.1 and 23.9 months after the IRE without signs of local recurrence. Conclusion: Percutaneous IRE in locally recurrent pancreatic cancer following curative resection is feasible, but should be regarded as a high-risk procedure that, at present, cannot be recommended outside of clinical trials. Further research is needed to select patients who might benefit from this treatment.
\end{abstract}

The majority of patients with pancreatic cancer are ineligible for surgery with curative intent due to metastatic and/or locally advanced disease (1). Among those resected with curative intent, recurrent disease is common, with isolated local recurrence in approximately half of those with recurrent disease (2). One reason why local recurrence is common is that many curative resections are in fact R1-resections (3).

This article is freely accessible online.

Correspondence to: Christopher Månsson, Department of Surgical Sciences, Uppsala University, 75185 Uppsala, Sweden. Tel: +46 186114505, Fax: +46 186114508, e-mail: christopher. mansson@surgsci.uu.se

Key Words: Irreversible electroporation, pancreatic cancer, recurrence, interventional ultrasonography.
Local treatment for local recurrence seems logical but is insufficiently studied. A study with 18 patients evaluated chemoradiotherapy with a survival rate of 17.5 months from the start of treatment and 27.2 months from diagnosis (4). Stereotactic body radiation therapy (SBRT) in 51 patients with a local recurrence after resection resulted in an overall survival of 16 months from SBRT and 36 months from diagnosis of pancreatic cancer (5).

Recently, several studies have reported the outcomes from irreversible electroporation (IRE) in locally advanced pancreatic cancer (6-9). However, to date there is very little experience from IRE for treatment of local recurrence after pancreatic resection. Of 14 patients treated with IRE, as reported by Naryanan et al., one had a local recurrence after a Whipple's resection. This patient had local progression one month after treatment and was alive with disease after 6.7 months (10).

With this background, we herein report the results of a clinical study to assess the safety and efficacy of percutaneous IRE in pancreatic cancer patients with locally recurrent disease following curative resection.

\section{Patients and Methods}

Patients. The study recruited patients with unequivocal locally recurrent pancreatic cancer following curative resection. The diagnosis was based on computed tomography (CT) with clear signs of unresectable tumour at the site of the resection of the mesenteric vessels. Patients were referred to us from several hospitals and if they had clear signs of a recurrence available for IRE treatment, they were offered inclusion in the study. Exclusion criteria were age $<18$ years, implanted electronic devices, ASA score IV, expected survival $<3$ months, pregnancy, epilepsy, severe heart disease, a diameter of the local recurrence of $>5.0 \mathrm{~cm}$ and metastatic disease. Ten patients were included in the study. The primary endpoint was complication rates and the secondary was overall survival from IRE treatment. The study was approved by the Uppsala Regional Ethics Committee, Sweden (Dnr 2013/254).

Treatment and post-treatment surveillance. The AngioDynamics (Queensbury, NY, USA) IRE machine was used for delivery of the 
Table I. Patient demographics before irreversible electroporation (IRE).

\begin{tabular}{|c|c|c|c|c|c|c|c|}
\hline $\begin{array}{l}\text { Patient } \\
\text { number }\end{array}$ & Gender & $\begin{array}{l}\text { Age at } \\
\text { IRE }\end{array}$ & $\begin{array}{c}\text { Type of } \\
\text { pancreatic } \\
\text { resection }\end{array}$ & $\begin{array}{c}\text { Radicality } \\
\text { at } \\
\text { surgery }\end{array}$ & $\begin{array}{c}\text { Adjuvant } \\
\text { chemotherapy } \\
\text { after resection }\end{array}$ & $\begin{array}{c}\text { Time between } \\
\text { surgery and local } \\
\text { recurrence (months) }\end{array}$ & $\begin{array}{l}\text { Time between local } \\
\text { recurrence and } \\
\text { IRE (months) }\end{array}$ \\
\hline 1 & Female & 55 & PD & $\mathrm{R} 1$ & $\begin{array}{l}\text { Capecitabine, oxaliplatin, } \\
\text { 5-fluorouracil, gemcitabine }\end{array}$ & 26.9 & 20.1 \\
\hline 2 & Male & 81 & $\mathrm{PD}$ & R0 & Gemcitabine & 22.4 & 1.8 \\
\hline 3 & Female & 81 & PD & R0 & Gemcitabine & 12.0 & 1.8 \\
\hline 4 & Male & 81 & DP & R0 & Gemcitabine & 11.3 & 1.2 \\
\hline 5 & Female & 69 & PD & $\mathrm{R} 0$ & Gemcitabine & 20.8 & 4.1 \\
\hline 6 & Female & 49 & DP & $\mathrm{R} 1$ & Gemcitabine, 5-fluorouracil, oxaliplatin & 8.4 & 3.3 \\
\hline 7 & Female & 58 & PD & $\mathrm{R} 1$ & Gemcitabine & 14.6 & 1.6 \\
\hline 8 & Male & 58 & $\mathrm{PD}$ & $\mathrm{R} 1$ & Gemcitabine, 5-fluorouracil, oxaliplatin & 3.9 & 3.9 \\
\hline 9 & Female & 63 & PD & R0 & Gemcitabine, nab-paclitaxel & 14.8 & 5.8 \\
\hline 10 & Male & 64 & PD & $\mathrm{R} 1$ & Gemcitabine, nab-paclitaxel & 16.4 & 4.9 \\
\hline
\end{tabular}

PD: Pancreaticoduodenectomy; DP: distal pancreatectomy.

electrical pulses. Percutaneous IRE needles were placed around the tumour with ultrasound guidance under general anaesthesia with deep neuromuscular block. After a test with 10 pulses with 1,200 $\mathrm{V} / \mathrm{cm}$, the current was adjusted to achieve an end current of 30-50 Amp. However, it is not possible to exceed $1,500 \mathrm{~V} / \mathrm{cm}$. After the 10 test pulses, another 90 pulses were given as treatment. The needles were placed $2 \mathrm{~cm}$ apart which created an ablation field of $3 \mathrm{~cm}$ in diameter. If the presumed field was not large enough to cover all the tumor, a needle was also placed in the centre of the tumour. After the first treatment, the needles were pulled back and another treatment cycle was started. After the treatment, patients were observed as in-patients for at least three days for any immediate complications, and these were scored according to the Dindo-Clavien scale. Adverse effects reported up to 30 days following IRE were assessed with respect to their relationship to IRE. A Dindo-Clavien complication score $>2$ was considered severe (11).

Follow-up. After the IRE treatment, the patients were followed for recurrent disease every third month with both IV contrast-enhanced ultrasound and thoracic and abdominal IV contrast-enhanced CT until there were clear signs of local recurrence of metastatic disease, at which time surveillance was discontinued. Local recurrence was defined as an expanding and/or contrast-enhanced lesion at the site of ablation. If there were radiological signs of tumour at the treated site at the first three-month assessment after IRE ablation, the ablation was considered incomplete. In the case of incomplete ablation at three months, no further IRE ablation was scheduled. If there were clinical signs of complications or progressive disease, an additional radiological examination was performed.

\section{Results}

Patients. Ten patients, four men and six women, were included and underwent IRE between December 2013 and January 2018. Their average age was 63.5 years (range $=55$ 81 years). All had adjuvant chemotherapy after curative pancreatic resection which was, however, R1 in five patients.
Median time from surgery to diagnosis of local recurrence was 14.7 months and from local recurrence to IRE, 3.6 months. Patient characteristics prior to the IRE are summarized in Table I.

IRE-related adverse events. Median hospital stay following IRE was 4 days (range=3-29 days) (Table II) including hospital stay at the local hospital. Two patients suffered severe IRE-related adverse events. Patient number 6 had occlusion of the portal vein prior to IRE, and also had occlusion of the hepatic artery immediately after IRE plus the superior mesenteric artery on postoperative day 5. This led first to liver and later bowel ischaemia which were treated with repeated arterial stenting. This patient died 3.6 months after IRE from complications related to this adverse event and is deemed as an IRE-related Clavien-Dindo grade 5. Autopsy showed lung and liver metastases, abdominal carcinosis and tumour growth in the pancreas, indicating incomplete ablation. Patient number 5 had a gram-positive sepsis, high plasma amylase count after IRE, and later also peritonitis. Laparotomy was performed and showed signs of pancreatitis. A percutaneous drain was placed, which contained amylase and which later became a pancreatic fistula which was treated conservatively.

Two patients had Clavien-Dindo grade 1 complications with one case of pain and one of diarrhoea after IRE.

IRE efficacy and survival. Contrast-enhanced ultrasound and CT with intravenous contrast showed a successful, complete ablation in five out of ten patients, i.e. those patients showed no signs of viable tumour at the three-month CT check, whereas five had signs of residual tumour at this time point. Median disease-free survival was 3.3 months; median overall survival after IRE was 16.5 months, and it was 42.7 months 
Table II. Results after irreversible electroporation (IRE).

\begin{tabular}{|c|c|c|c|c|c|c|}
\hline $\begin{array}{l}\text { Patient } \\
\text { number }\end{array}$ & $\begin{array}{c}\text { Time at } \\
\text { hospital after } \\
\text { IRE (days) }\end{array}$ & $\begin{array}{l}\text { Dindo-Clavien } \\
\text { complication } \\
\text { score }\end{array}$ & $\begin{array}{c}\text { Palliative } \\
\text { chemotherapy } \\
\text { after IRE }\end{array}$ & $\begin{array}{l}\text { Time to death } \\
\text { after surgery } \\
\text { (months) }\end{array}$ & $\begin{array}{l}\text { Time to death } \\
\text { after IRE } \\
\text { (months) }\end{array}$ & $\begin{array}{l}\text { Time to local } \\
\text { relapse after } \\
\text { IRE (months) }\end{array}$ \\
\hline 1 & 3 & 0 & No & 51.1 & 4.1 & - \\
\hline 2 & 5 & 0 & No & 42.7 & 18.5 & 3.1 \\
\hline 3 & 4 & 0 & Capecitabine & 26.1 & 12.3 & 3.3 \\
\hline 4 & 5 & 0 & Gemcitabine, capecitabine & 24.8 & 12.4 & 1.3 \\
\hline 5 & 29 & 3B & $\begin{array}{c}\text { Gemcitabine, nab-paclitaxel, } \\
\text { 5-fluorouracil, oxaliplatin }\end{array}$ & 49.6 & 24.7 & 3.2 \\
\hline 6 & 25 & 5 & No & 15.3 & 3.6 & - \\
\hline 7 & 4 & 1 & $\begin{array}{l}\text { 5-fluorouracil, oxaliplatin, } \\
\text { capecitabine, S-1, irinotecan }\end{array}$ & Alive after 58.2 & Alive after 42.1 & - \\
\hline 8 & 3 & 1 & 5-fluorouracil, oxaliplatin, irinotecan & 24.2 & 16.5 & 6.7 \\
\hline 9 & 4 & 0 & No & Alive after 44.4 & Alive after 23.9 & - \\
\hline 10 & 4 & 0 & Capecitabine, oxaliplatin & 37.7 & 13.6 & 3.2 \\
\hline
\end{tabular}

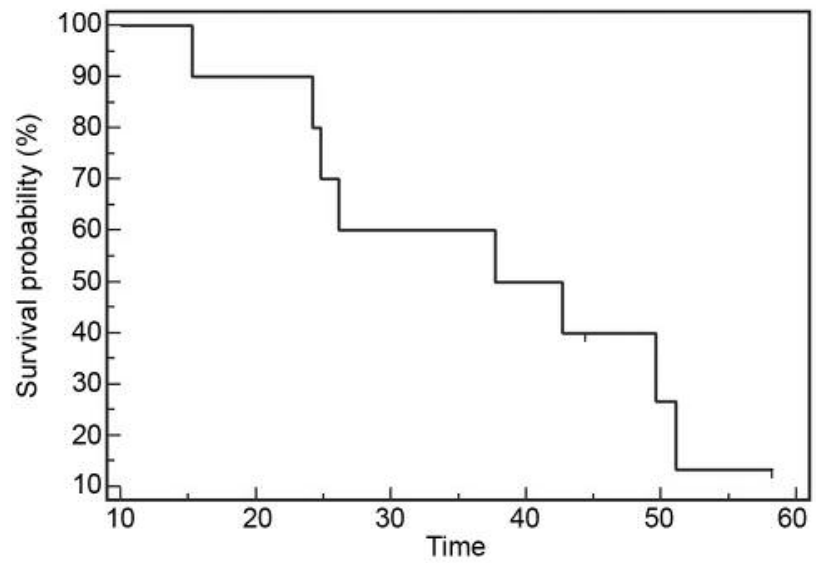

Figure 1. Kaplan-Meier curve showing overall survival in months after pancreatic resection.

from resection (Figures 1 and 2, Table II). Notably, two patients (numbers 7 and 9) are still alive at 42.1 and 23.9 months after IRE without signs of local recurrence, although number 7 has confirmed recurrent metastatic disease after 38.2 months. Six patients received palliative chemotherapy after the IRE treatment (Table II).

\section{Discussion}

The 16.5 month overall survival after IRE observed in this study compares favourably with the observed 9-month survival from diagnosis of local recurrence as reported in the follow-up of the ESPAC trial (2). Moreover, our results are similar to those observed for treatment with chemoradiotherapy and SBRT $(4,5)$. Two of our patients are still without local relapse

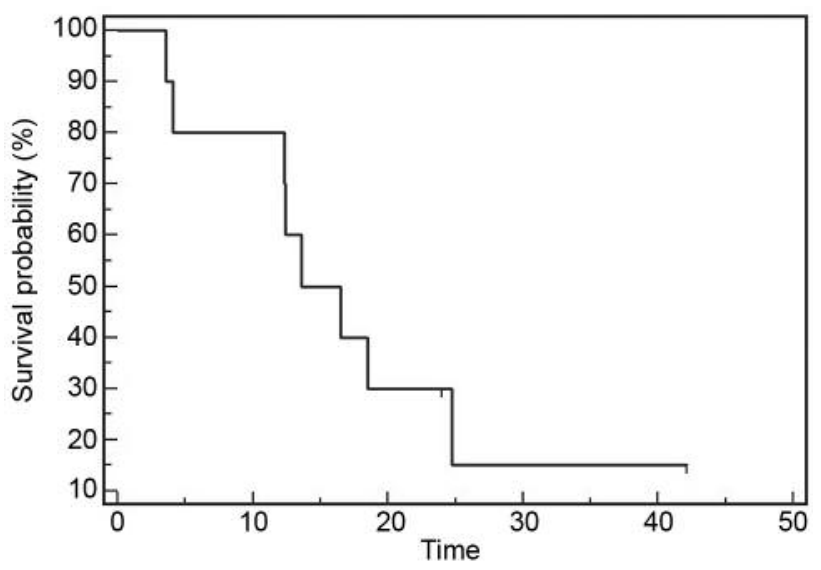

Figure 2. Kaplan-Meier curve showing overall survival in months after treatment with irreversible electroporation.

with one being alive five years from surgery. These observations seemingly indicate some benefit from the addition of local to systemic treatment of locally recurrent pancreatic cancer following curative surgery. However, given the small number and carefully selected patients, firm conclusions regarding any benefit of IRE so far in this situation are still pending and we cannot know for sure if we have improved the survival of the two patients that are still alive without local relapse.

To our knowledge, this was the first trial on IRE in locally recurrent pancreatic cancer following curative resection. However, the PANFIRE-2 trial, which was a prospective study mostly on primary locally advanced pancreatic cancer, also included 10 cases of recurrent disease after resection (12). The overall survival in those patients was 9.0 months 
from IRE and median overall survival from diagnosis of recurrence was 15 months. Those results are slightly inferior to ours and more in line with the outcomes of patients treated with palliative chemotherapy alone.

For additional comparison, there are some studies on surgical resection for local recurrences when contained in the remnant pancreas. In a recent study by Kim et al., the median survival from re-resection was 28.0 months (13). Patients not resected had a median survival of 12.0 months. Importantly, those resected only had a recurrence in the remnant pancreas, whereas in our study recurrence was on the mesenteric vessels and deemed unresectable.

Safety is the other side of the coin when drawing conclusions on IRE in locally recurrent pancreatic cancer. In our study, one patient had an occlusion of both the hepatic and superior mesenteric arteries following IRE. According to the principles for IRE, the arteries should be unaffected by IRE, so the occlusions observed raise questions regarding the overall safety of IRE. However, this patient had a tumour that was already borderline in size and IRE was executed with a large field with six needles and a pullback technique. This might have led to a swelling compressing the arteries followed by thrombosis.

There were two severe complications from IRE in this study and one might speculate that this could be due to a learning curve for the procedure. However, the interventional radiologist that conducted the IRE has performed a number of IRE treatments on locally advanced pancreatic cancer and liver tumours in our other studies $(8,14)$.

Given two severe complications among ten patients in our trial, we conclude that IRE for locally recurrent pancreatic cancer is associated with high risk for severe IRE-related complications and, thus, IRE at present is not justified for use in routine healthcare. In the PANFIRE-2 trial, there were 20 severe complications among the 50 patients treated. However, only 10 had local recurrences and the actual number of complications for this subgroup was not reported.

Another fundamental limitation for local treatments, including IRE, for locally recurrent pancreatic cancer is that in this setting the disease can be regarded as systemic disease in the majority of cases (2). Thus, the benefit from adding any kind of local treatment is probably very modest unless patients with isolated local disease can be selected for local treatment. However, this is difficult, as illustrated by our patient number six. This patient died 3.6 months after IRE, and the autopsy showed peritoneal metastases not radiologically observed at the time of IRE and no staging laparoscopy was done before the IRE. Thus, if IRE or any other local treatment for local recurrence of pancreatic cancer is to be considered, all possible means, including laparoscopy, are recommended to exclude the presence of systemic disease.

In our previous studies on IRE of primary locally advanced pancreatic cancer, there were six local recurrences in 48 patients within three months $(8,14)$ compared with five out of 10 in the present study. This indicates, not unexpectedly, that a local recurrence after resection is more advanced and difficult to treat locally despite similar radiological disease extension.

The most obvious limitation to our trial is that it is small and non-randomized and could rather be regarded as a case series reflecting feasibility of IRE with the general problem of patient selection for the observations made. Furthermore, inclusion time extended for several years and the principles for use of systemic chemotherapy before and after IRE were not defined in the protocol.

\section{Conclusion}

IRE in locally recurrent pancreatic cancer following curative resection is technically feasible but should, at present, be regarded as a high-risk procedure. Although there are some signs of potential benefit from IRE in this situation, the procedure cannot be recommended outside of clinical trials since such finding has not yet been confirmed and there are obvious complications related to the treatment. More research is needed to select patients who might benefit, notably those few patients without simultaneous systemic recurrence.

\section{Conflicts of Interest}

Anders Nilsson has received travel funding from AngioDynamics for lectures.

\section{Authors' Contributions}

CM: Study design, data collection, preparation of manuscript, final approval of manuscript; AN: study design, data collection, preparation of manuscript, final approval of manuscript; PN: study design, preparation of manuscript, final approval of manuscript; BMK: study design, data collection, preparation of manuscript, final approval of manuscript.

\section{Acknowledgements}

The Authors thank Mandy Trickett for language editing.

\section{References}

1 Keane MG, Bramis K, Pereira SP and Fusai GK: Systematic review of novel ablative methods in locally advanced pancreatic cancer. World J Gastroenterol 20(9): 2267-2278, 2014. PMID: 3942832. DOI: $10.3748 /$ wjg.v20.i9.2267

2 Jones RP, Psarelli EE, Jackson R, Ghaneh P, Halloran CM, Palmer DH, Campbell F, Valle JW, Faluvi O, Cunnigham D, Wadsley J, Darby S, Meyer T, Gillmore R, Anthoney A, Lind P, Glimelius B, Falk S, Izbicki JR, Middleton GW, Cummins S, Ross PJ, Wasan H, McDonald A, Crosby T, Ting Y, Patel K, Sherriff D, Soomal 
R, Borg D, Sothi S, Hammel P, Lerch MM, Mayerle J, Tjaden C, Strobel O, Hackert T, Büchler MW and Neoptolemos JP: Patterns of recurrence after resection of pancreatic ductal adenocarcinoma: a secondary analysis of the ESPAC-4 randomized adjuvant chemotherapy trial. JAMA Surg 154(11): 1038-1048, 2019. PMID: 6727687. DOI: 10.1001/jamasurg.2019.3337

3 Zhang Y, Frampton AE, Kyriakides C, Bong JJ, Habib N, Ahmad $\mathrm{R}$ and Jiao LR: Loco-recurrence after resection for ductal adenocarcinoma of the pancreas: predictors and implications for adjuvant chemoradiotherapy. J Cancer Res Clin Oncol 138(6): 1063-1071, 2012. PMID: 22392075. DOI: 10.1007/s00432-0121165-7

4 Wilkowski R, Thoma M, Bruns C, Duhmke E and Heinemann $\mathrm{V}$ : Combined chemoradiotherapy for isolated local recurrence after primary resection of pancreatic cancer. JOP 7(1): 34-40, 2006. PMID: 16407616.

5 Ryan JF, Groot VP, Rosati LM, Hacker-Prietz A, Narang AK, McNutt TR, Jackson J, Le Dt, Jaffee EM, Zheng L, Laheru DA, He J, Pawlik TM, Weiss MJ, Wolfgang CL and Herman JM: Stereotactic body radiation therapy for isolated local recurrence after surgical resection of pancreatic ductal adenocarcinoma appears to be safe and effective. Ann Surg Oncol 25(1): 280-289, 2018. PMID: 29063299. DOI: 10.1245/s10434-017-6134-6

6 Belfiore MP, Ronza FM, Romano F, Ianniello GP, De Lucia G, Gallo C, Marciano C, Di Gennaro TL and Belfiore G: Percutaneous CT-guided irreversible electroporation followed by chemotherapy as a novel neoadjuvant protocol in locally advanced pancreatic cancer: Our preliminary experience. Int J Surg 21(9) Suppl 1: 3439, 2015. PMID: 26118600. DOI: 10.1016/j.jjsu.2015.06.049

7 Martin RC, 2nd, Kwon D, Chalikonda S, Sellers M, Kotz E, Scoggins C, McMasters KM, and Watkins K: Treatment of 200 locally advanced (Stage III) pancreatic adenocarcinoma patients with irreversible electroporation: Safety and efficacy. Ann Surg 262(3): 486-494, 2015. PMID: 26258317. DOI: 10.1097/ sla. 0000000000001441

8 Mansson C, Brahmstaedt R, Nilsson A, Nygren P and Karlson BM: Percutaneous irreversible electroporation for treatment of locally advanced pancreatic cancer following chemotherapy or radiochemotherapy. Eur J Surg Oncol 42(9): 1401-1406, 2016. PMID: 26906114. DOI: 10.1016/j.ejso.2016.01.024
9 Narayanan G, Hosein PJ, Beulaygue IC, Froud T, Scheffer HJ, Venkat SR, Echenique AM, Hevert EC, Livingstone AS, RochaLima CM, Merchan JR, Levi JU, Yrizarry JM and Lencioni R: Percutaneous image-guided irreversible electroporation for the treatment of unresectable, locally advanced pancreatic adenocarcinoma. J Vasc Interv Radiol 28(3): 342-348, 2017. PMID: 27993507. DOI: 10.1016/j.jvir.2016.10.023

10 Narayanan G, Hosein PJ, Arora G, Barbery KJ, Froud T, Livingstone AS, Franceschi D, Rocha Lima CM and Yrizarry J: Percutaneous irreversible electroporation for downstaging and control of unresectable pancreatic adenocarcinoma. J Vasc Interv Radiol 23(12): 1613-1621, 2012. PMID: 23177107. DOI: 10.1016/j.jvir.2012.09.012

11 Dindo D, Demartines N and Clavien PA: Classification of surgical complications: a new proposal with evaluation in a cohort of 6336 patients and results of a survey. Ann Surg 240(2): 205-213, 2004. PMID: 15273542. DOI: 10.1097/01.sla.0000133083.54934.ae

12 Ruarus AH, Vroomen L, Geboers B, van Veldhuisen E, Puijk RS, Nieuwenhuizen S, Besselink MG, Zonderhuis BM, Kazemier G, de Gruijl TD, van Lienden KP, de Vries JJJ, Scheffer HJ and Meijerink MR: Percutaneous irreversible electroporation in locally advanced and recurrent pancreatic cancer (PANFIRE-2): A multicenter, prospective, single-arm, Phase II study. Radiol 294(1): 2012-220, 2020. PMID: 31687922. DOI: 10.1148/radiol.2019191109

13 Kim YI, Song KB, Lee YJ, Park KM, Hwang DW, Lee JH, Shin SH, Kwon JW, Ro JS and Kim SC: Management of isolated recurrence after surgery for pancreatic adenocarcinoma. Br J Surg 106(7): 898-909, 2019. PMID: 31162655. DOI: 10.1148/radiol.2019191109

14 Mansson C, Brahmstaedt R, Nygren P, Nilsson A, Urdzik J and Karlson BM: Percutaneous irreversible electroporation as firstline treatment of locally advanced pancreatic cancer. Anticancer Res 39(5): 2509-2512, 2019. PMID: 31092446. DOI: 10.21873/anticanres.13371
Received March 15, 2020

Revised March 29, 2020

Accepted March 31, 2020 